\title{
Lack of association between methylenetetrahydrofolate reductase C677T polymorphism, HPV infection and cervical intraepithelial neoplasia in Brazilian women
}

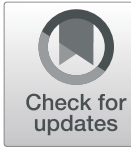

Nayara Nascimento Toledo Silva ${ }^{1 *} \mathbb{D}$, Adriano de Paula Sabino ${ }^{2}$, Alexandre Tafuri ${ }^{3}$ and Angélica Alves Lima ${ }^{1}$

\begin{abstract}
Background: Cervical cancer has high prevalence and mortality rates in worldwide female population. Persistent infection by high-risk Human Papillomavirus (hr-HPV) is the main cause of this cancer. However, many environmental, genetical, and epigenetical cofactors can modulate viral infection and cervical carcinogenesis. Methylenetetrahydrofolate reductase (MTHFR) C677T polymorphism is a genetic factor that has been associated with many pathologies, including cancer. Nevertheless, studies with cervical cancer presented controversial results, and varied according to ethnicity. Thus, the aim of this study was to determine association between MTHFR C677T polymorphism, Human Papillomavirus (HPV) infection and cervical cancer.
\end{abstract}

Methods: A case-control study was performed with 150 histological cervical samples. Case group were divided in Cervical Intraepithelial Neoplasia (CIN) grade I $(n=30)$, CIN II $(n=30)$, CIN III $(n=30)$, and Squamous Cervical Carcinoma (SCC) $(n=30)$. Control group was composed by 30 samples without lesion, presenting cervicitis. HPV detection was performed by conventional Polymerase Chain Reaction (PCR) with SPF primers set, and by real-time PCR specific for HPV 16 and hr-HPV. MTHFR C677T polymorphism was analyzed by PCR followed by Restriction Fragment Length Polymorphism (RFLP).

Results: Frequency of MTHFR CC genotype was 72.7\% ( $n=109)$, CT 23.3\% $(n=35)$ and $T$ 4.0\% $(n=6)$. Polymorphic T allele frequency was 15.7\%. No statistically significant association was observed between MTHFR C677T polymorphism and presence of pre-neoplastic or neoplastic cervical lesions. Similar frequencies of T allele was observed in control (23.3\%) and cases (13.3\%) groups ( $p=0.174)$. In addition, there was no statistically significant association between MTHFR C677T polymorphism and viral infection, even considering hr-HPV or HPV 16 positivity. Conclusion: MTHFR C677T polymorphism was not associated with cervical cancer and HPV infection.

Keywords: HPV, Cervical Cancer, SNP, MTHFR C677T polymorphism, Folate metabolism

\section{Background}

Cervical cancer is the fourth most common cancer in women worldwide, with 529,000 new cases, and 275,000 deaths each year. Most cases occur in developing countries. On the other hand, lower incidence rates of this tumor occur in developed countries, where programs for

\footnotetext{
* Correspondence: nayarants@gmail.com

${ }^{1}$ Programa de Pós-Graduação em Ciências Farmacêuticas, Departamento de Análises Clínicas, Universidade Federal de Ouro Preto, Ouro Preto, Minas Gerais 35400-000, Brazil

Full list of author information is available at the end of the article
}

prevention, screening and treatment are well established [1]. In Brazil, cervical cancer is the third type of tumor that most often affects female population, with an annual mortality rate of 5000 women. Furthermore, 16,370 new cases were estimated in Brazil for 2018 [2].

Persistent infection with high-risk Human Papillomavirus (hr-HPV) is the main cause of cervical cancer, and 99.7\% of cases are associated with the virus [3]. However, only $10 \%$ of women presenting HPV infection will develop precancerous lesions, and less than $1 \%$ of these abnormalities will progress, leading to cervical tumor

(c) The Author(s). 2019 Open Access This article is distributed under the terms of the Creative Commons Attribution 4.0 International License (http://creativecommons.org/licenses/by/4.0/), which permits unrestricted use, distribution, and reproduction in any medium, provided you give appropriate credit to the original author(s) and the source, provide a link to the Creative Commons license, and indicate if changes were made. The Creative Commons Public Domain Dedication waiver (http://creativecommons.org/publicdomain/zero/1.0/) applies to the data made available in this article, unless otherwise stated. 
[4]. Thus, presence of other factors in cervical cancer development is necessary in addition to HPV infection. Currently, several genetics, epigenetics, and environmental factors had been studied $[5,6]$.

Methylenetetrahydrofolate Reductase (MTHFR) is an enzyme that plays a central role in folate metabolism, important in cell replication and gene expression [7]. C677T polymorphism was identified by Frost and colleagues in 1995, and leads to the exchange of cytosine (C) to thymine (T) at codon 222, resulting in reduced enzymatic activity of MTHFR [8]. This Single Nucleotide Polymorphism (SNP) is the most common MTHFR genetic variant found in population, wherein frequency of the TT polymorphic genotype may vary according to ethnicity $[8,9]$. In US population, frequency of polymorphic allele is approximately $35 \%$, while Asian and Caucasian populations present 12 to $15 \%$ rates of TT individuals, and greater than $50 \%$ for CT genotype. Moreover, the incidence of polymorphic genotype is less than 1\% among American Afro-descendants [10].

MTHFR C677T polymorphism has been associated with development of cardiovascular diseases, defects in the neural tube formation, psychiatric disorders and various cancers [9]. The presence of polymorphic $\mathrm{T}$ allele was considered a protective factor for colorectal cancer, acute lymphoblastic leukemia in adults, and some leukemias and lymphomas in children. However, MTHFR C677T polymorphism has been identified as a risk factor for breast, endometrium, esophagus, stomach, pancreas, and bladder cancer $[11,12]$. Few studies have been conducted to evaluate the frequency of MTHFR C677T polymorphism and its association with cervical cancer. Besides, results were controversial and inconclusive, varying according to country and ethnicity $[13,14]$.

Thus, the aim of this study was to determine association between MTHFR C677T polymorphism, HPV infection and cervical cancer in Brazilian women.

\section{Methods}

\section{Samples selection}

Samples were collected between 2006 and 2011, from Brazilian women in Minas Gerais State, Brazil, a population with highly mixed ethnicities. Rating Histology of Richart was used to classify the samples [15]. Tafuri Laboratory kindly provided these blocks of cervical biopsies. Thirty samples presenting Squamous Cervical Cancer (SCC) were provided to perform the study. Therefore, we composed the other groups [Control, Cervical Intraepithelial Neoplasia grade I (CIN I), CIN II, and CIN III], with the same number of samples. These were chosen randomly from database of Laboratory Tafuri, pairing the age according to the patients from SCC group.

Thus, case group was composed of 120 histological samples divided into CIN I $(n=30)$, CIN II $(n=30)$, CIN
III $(n=30)$, and SCC $(n=30)$. Thirty samples without cervical dysplasia was considered the control group (Fig. 1).

This study was approved by Research Ethics Committee of the Federal University of Ouro Preto.

\section{Preparation and DNA extraction}

DNA extraction was performed using three histological sections of $10 \mu \mathrm{m}$ of each biopsy block (Fig. 1). Firstly, the paraffin was removed with xylene and absolute ethanol. DNA extraction was performed with QIAamp DNA FFPE Tissue Kit (Qiagen, Hilden, Germany). Concentration and purity of extracted DNA were determined by NanoDrop $2000^{\circ}$ spectrophotometer (Thermo Scientific, Waltham, Massachusetts, United States of America).

\section{HPV detection}

Generic HPV detection was performed by PCR with SPF primers set [16], that detect all HPV types (Fig. 1). Protocol and PCR conditions were presented in Tables 1 and 2, respectively. PCR products were identified using agarose gel electrophoresis stained with GelRed ${ }^{\circ}$ (Biotium, Fremont, California, United States of America). Presence of HPV infection was confirmed with fragment amplification of $65 \mathrm{bp}$ (Fig. 2).

HPV genotyping was performed by real-time PCR with Bio Gene HPV Alto Risco PCR ${ }^{\circ}$ (Bioclin, Belo Horizonte, Minas Gerais, Brazil). This assay is based on qualitative detection of hr-HPV $(16,18,31,33,35,39,45,51,52$, $56,58,59,66$ e 68 ), according to recommendations of manufacturer, and distinguish the presence of HPV 16.

\section{MTHFR C677T polymorphism analysis}

MTHFR C677T polymorphism was analyzed by PCR followed by Restriction Fragment Length Polymorphism (RFLP) (Fig. 1), as described by Silva et al. [17]. Fragments generated by RFLP were analyzed by capillary electrophoresis performed on the QIAxcel Advanced System ${ }^{\circ}$ (Qiagen, Hilden, Germany). CC individuals presented one fragment of $198 \mathrm{bp}$, heterozygotes (CT) presented two fragments of $198 \mathrm{bp}$ and $175 \mathrm{bp}$, and polymorphic individuals (TT) presented one fragment of $175 \mathrm{bp}$.

\section{Statistical analysis}

Data were tabulated by Microsoft Office Excel ${ }^{\bullet}$ (Microsoft, Redmond, Washington, United States of Amercia,) and analyzed by Statistical Package for the Social Sciences $^{\circ} 17.0$ (International Business Machines, New York, United States of America).

Descriptive statistics were performed to evaluate the frequency of MTHFR genotypes and HPV infection. Allelic frequency was calculated by Genepop software [18] 


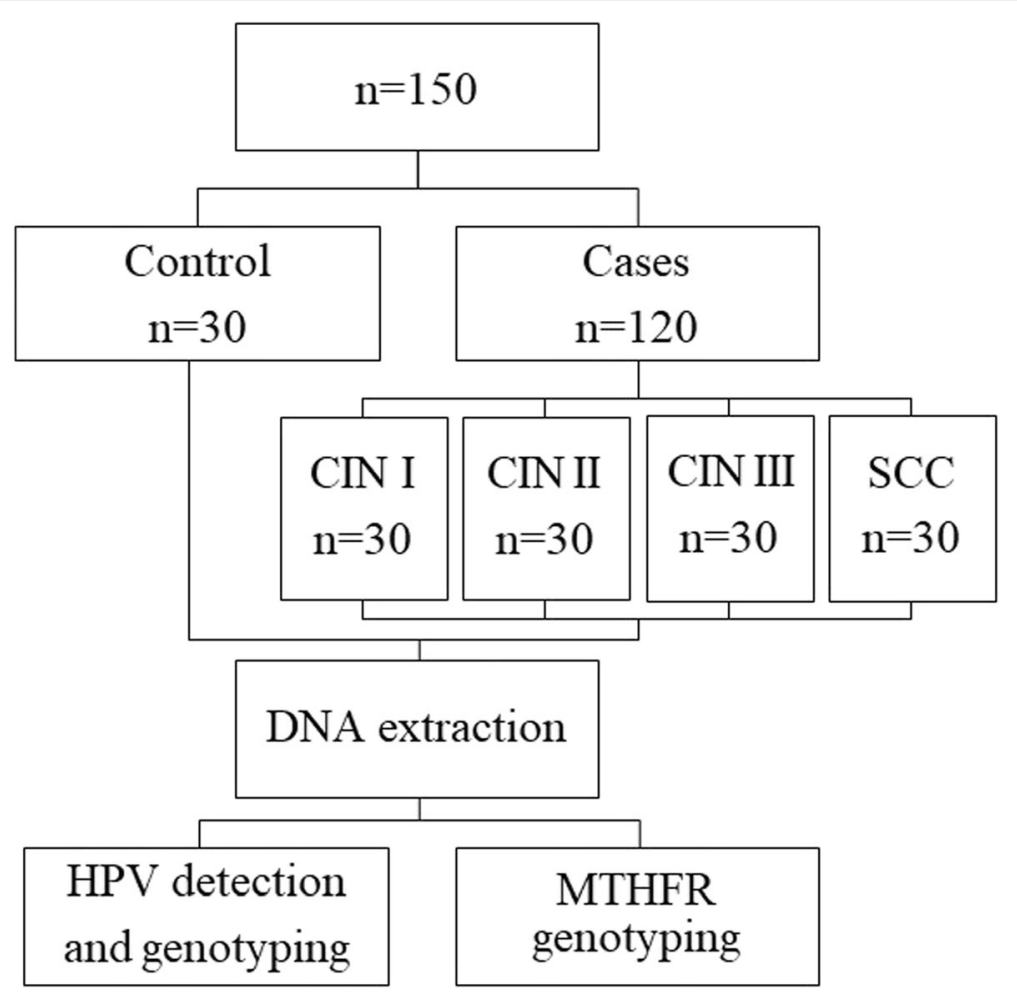

Fig. 1 Study flow diagram. CIN: Cervical Intraepithelial Neoplasia; HPV: Human Papillomavirus; MTHFR: Methylenetetrahydrofolate Reductase

Frequency distribution and $\mathrm{X}^{2}$ test following MonteCarlo simulation were used to compare the groups.

To evaluate the effect of age on the association between MTHFR C677T polymorphism and cervical carcinogenesis, samples were divided into two age groups using 30 years old as the cut off. After this age, oncogenic HPV infection is more persistent, and women are more likely to have pre-invasive lesion.

Hardy-Weinberg Equilibrium (HWE) of MTHFR genotypes frequencies was calculated by Hardy-Weinberg equilibrium calculator including analysis for ascertainment bias [19].

$p$ values $<0.05$ were considered as evidence of a significant association in all tests and 95\% confidence interval was calculated when appropriate.

Table 1 PCR protocol for HPV detection with SPF primers set

\begin{tabular}{ll}
\hline Reagents & Protocol \\
\hline PCR Master Mix ${ }^{\oplus^{\mathrm{a}}}$ & $12.5 \mu \mathrm{l}$ \\
Primers $^{\mathrm{b}}(10 \mathrm{pmol} / \mu \mathrm{l})$ & $0.5 \mu \mathrm{l}$ (each) \\
Sample (DNA) & $25 \mathrm{ng}$ \\
Final volume & $25 \mu \mathrm{l}$ \\
\hline
\end{tabular}

${ }^{a} 0.2 \mathrm{mM}$ each deoxyribonucleotide (dNTP), $1.5 \mathrm{mM} \mathrm{MgCl}$ and 1.0 unit of Taq DNA (Promega, Madison, Wisconsin, United States of America)

${ }^{b}$ Nucleotide sequences ( $5^{\prime}-3$ '): SPF 1A: GCiCAGGGiCACAATAATGG; SPF 1B: GCICAGGGiCATAACAATGG; SPF 1C: GCICAGGGiCATAATAATGG; SPF 1D: GCICAAGGiCATAATAATGG; SPF 2B: GTIGTATCIACAACAGTAACAAA; SPF 2D: GTIGTATCIACTACAGTAACAAA

\section{Results}

Age range of women varied from 15 to 82 years, and mean and standard deviation of case and control groups were respectively $39.1 \pm 13.5$ and 40,5 \pm 15.9 years.

Genotypes frequencies of MTHFR C677T polymorphism were $72.7 \%(n=109), 23.3 \%(n=35)$ and $4.0 \%(n=6)$ of CC, CT and TT, respectively. Frequency of polymorphic $\mathrm{T}$ allele was $15.7 \%$. Distribution of genotypes was found under HWE $\left(\mathrm{X}^{2}=0.14, p=.0708\right)$.

HPV infection was found in $96.7 \%(n=145)$ of samples. Most of samples presented hr-HPV infection $(61.3 \%, n=92)$. Beside this, HPV 16 positivity was $28.0 \%$ $(n=42)$. However, no statistically significant difference was observed between distribution of MTHFR genotypes or alleles and HPV infection status (Fig. 3).

There was no statistically significant association between distribution of MTHFR genotypes $(p=0.212)$ and alleles $(p=0.174)$, and presence of CIN or SCC (case

Table 2 PCR condition for HPV detection with SPF primers set

\begin{tabular}{llll}
\hline Number of cycles & Temperature $\left({ }^{\circ} \mathrm{C}\right)$ & Time (minutes) & Stage \\
\hline 1 & 94 & 1 & Denaturation \\
40 & 94 & 1 & Denaturation \\
& 45 & 1 & Annealing \\
& 72 & 1 & Extension \\
1 & 72 & 5 & Final Extension \\
\hline
\end{tabular}




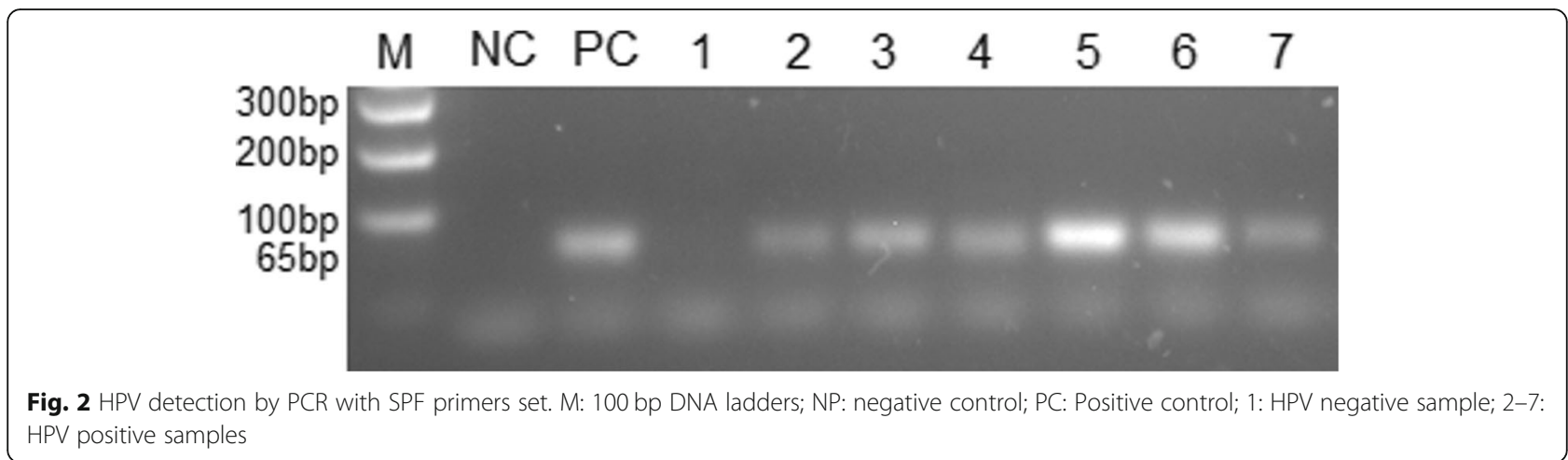

group) (Fig. 4). Similarly, no association was observed according to lesions degree in uterine cervix (genotypes: $p=0.600$; alleles: $p=0.669$ ) (Fig. 4). Same results were obtained analyzing only HPV, hr-HPV or HPV 16 positive samples (results not showed).

To evaluate the effect of age on the association between MTHFR C677T polymorphism and cervical carcinogenesis, samples were divided into two age groups: $\leq 30$ and $>30$ years. However, results did not show significant differences $(p>0.05)$ between distribution of genotypic and allelic frequencies and presence of cervical abnormalities according age group (Fig. 5).

\section{Discussion}

MTHFR C677T polymorphism may modify the susceptibility to carcinogenesis by modulating the availability of 5,10-methylenetetrahydrofolate at different sites of folate metabolism. This coenzymatic form of folate plays a central role in folate metabolism, because 5,10-methylenetetrahydrofolate can be (a) directly transferred to deoxyuridine monophosphate (dUMP) in thymidylate synthesis; (b) oxidized to 10-formyltetrahydrofolate for de novo synthesis of purines; or (c) reduced to 5methyltetrahydrofolate by MTHFR for methionine synthesis. Thus, reduction of enzymatic activity of MTHFR caused by C677T polymorphism may result in a lower synthesis rate of 5-methyltetrahydrofolate, leading to an increase availability of 5,10-methylenetetrahydrofolate for nucleotide production, which is essential for DNA synthesis and repair. In contrast, a lower proportion of 5 -methyltetrahydrofolate is available for the methylation pathway, affecting genic expression [20, 21].

However, although MTHFR C677T polymorphism may be linked to carcinogenesis by altering nucleotide synthesis, and DNA methylation pattern, in this study it was not possible to observe association between the presence of polymorphic genotype or allele, and cervical cancer. Other authors have also found no relationship between polymorphism in MTHFR gene and cervical carcinogenesis [22-31]. However, studies performed with women from United States and Mexico indicated the presence of the polymorphism as a protective factor for cervical cancer development [21,32]. Furthermore, a recent study in Iran also showed the presence of this SNP as a protective factor for cervical cancer [33].

In Brazil, only one study had been performed to evaluate the relationship between MTHFR C677T polymorphism and cervical cancer [34]. The authors analyzed data of 950 women attended in Brazilian Cancer Control Institute and Pérola Byington Hospital, both located in São Paulo, from 2003 to 2005. Unlike our result, Tomita et al. [34] observed the presence of MTHFR C677T polymorphism as a risk factor for cervical cancer. This difference may be occurred because Brazil is a country of great territorial extension, in which a highly mixed population is observed, presenting differences not only between its geographic regions but also between the states that compose them. Meta-analyses observed that C677T MTHFR polymorphism may be associated with cervical carcinogenesis in a different way according to ethnicity. This SNP was considered risk factor for cervical cancer among Asiatic women, but protection factor for Caucasian [13, 14, 35, 36].

No association between HPV infection and C677T polymorphism in MTHFR gene were observed. We did not find other studies performed with Brazilian women, and analyzing association between MTHFR C677T polymorphism and viral infection. However, similar results were obtained with Indian population [24,37]. On the other hand, studies conducted in United States and Romania indicated the presence of MTHFR C677T polymorphism as a risk factor for HPV infection [38, 39]. In contrast, Hajiesmaeil and colleagues [33] observed CT genotype as a protective factor for viral infection between Iranian women.

Age is a cofactor that could also be considered. Development of cervical cancer begins with hr-HPV infection. If infection persists for 1 or 2 years, cervical abnormalities may occur. Only about $10 \%$ viral infection progress, leading to low-grade lesions. Approximately $2 \%$ of infected women have high-grade cervical lesions after years of persistent infection. 


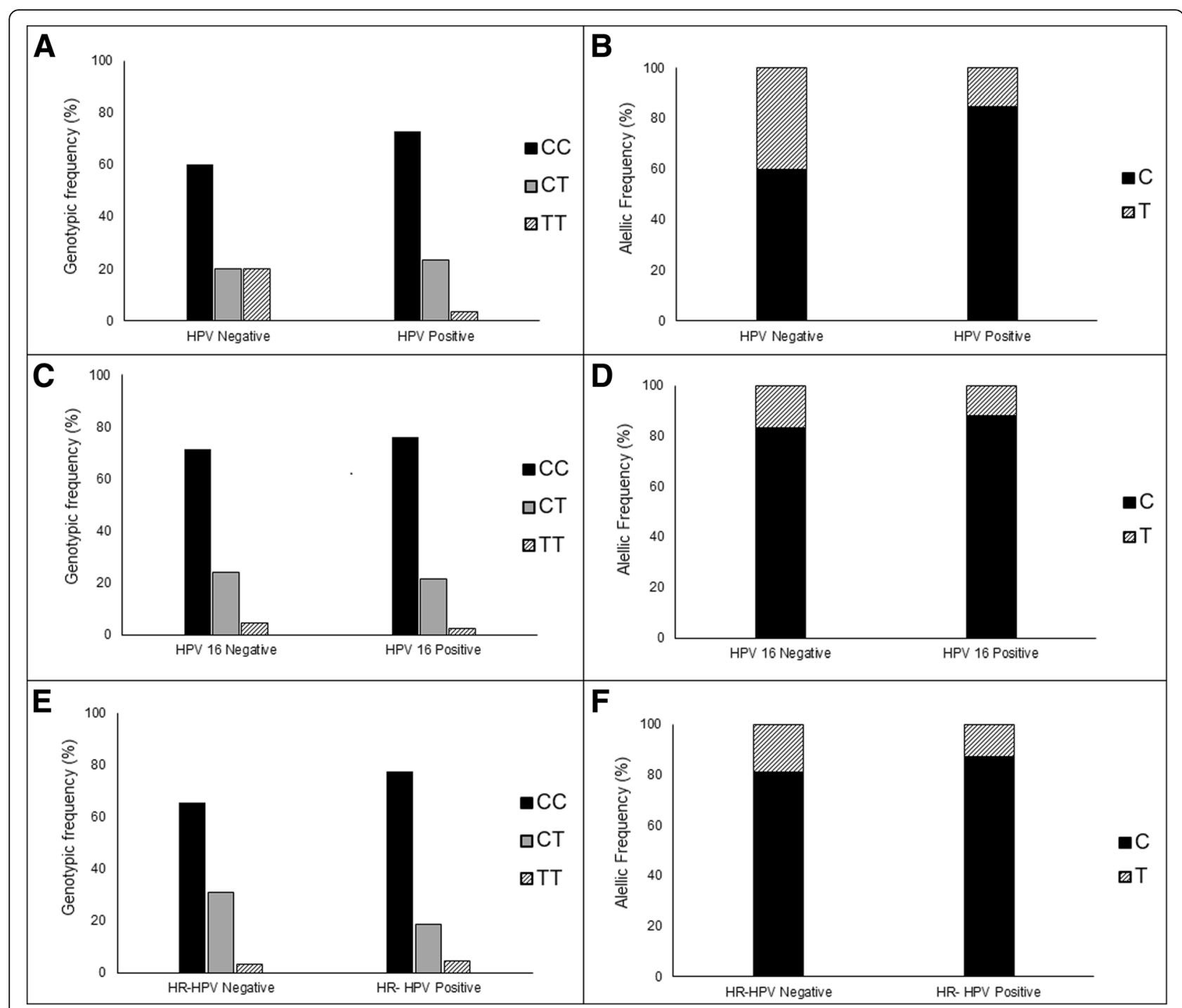

Fig. 3 MTHFR genotypic and allelic frequency in relation to HPV infection. Frequency of CC, CT and TT genotypes (a, $\mathbf{c}, \mathbf{e})$, and $\mathbf{C}$ and T alleles (b, d, $\mathbf{f})$ according HPV infection (a, b), HPV 16 infection (c, d), and hr-HPV infection (e, $\mathbf{f})$

High-grade abnormalities usually expand laterally around the transformation zone of cervical tissue, leading to invasive squamous cell carcinoma. Thus, there are more likely age groups for each stage of cervical cancer, with the highest prevalence of HPV infection occurring during adolescence and early adulthood, while the highest incidence of high-grade lesions is seen in women aged between 25 and 35 years. Carcinoma occurs predominantly between 45 and 60 years of age. Moreover, oncogenic HPV infection is more persistent in women aged 30 years or older, age group that women are more likely to have pre-invasive lesions [4, 40].

However, we did not observe significant difference in distribution of MTHFR genotype between cases and controls in both group ages evaluated $(\leq 30$ and $>30$ years old). On the other hand, Sull and colleagues [41] concluded that the presence of the polymorphic genotype increases the risk of developing cervical cancer in Korean women younger than 40 years.

Some meta-analysis found that MTHFR C677T polymorphism is associated with cervical carcinogenesis differently according to ethnic group, acting as a risk factor for Asian, and as a protective factor for Caucasian [13, 14]. However, our study was performed with Brazilian women, a population composed by many mixed ethnicities. Thus, was not possible analyzing the role of polymorphism in cervical cancer development considering different ethnicities separately. 


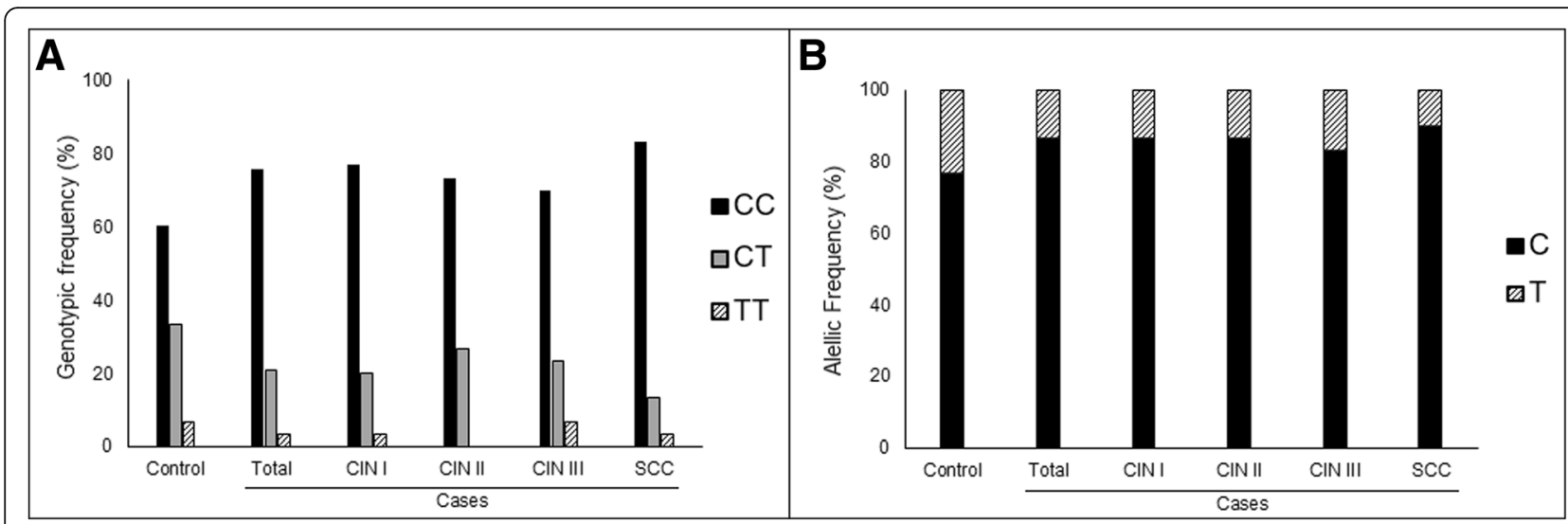

Fig. 4 MTHFR genotypic and allelic frequency according to cervical abnormalities. Frequency of CC, $C T$ and $T$ genotypes (a), and C and T alleles (b) in Control and Case groups (Total, CIN I, CIN II, CIN III, and SCC)

Besides, cervical carcinogenesis is a multifactorial disease, although HPV infection is the main factor. Consequently, lack of information about other factors must be considered, like sexual behavior, multiparity, smoking and drinking habits, presence of other sexually transmitted diseases, and other genetic factors [6].
Moreover, absence of data on serum folate of participants should be taken into account, since effect of MTHFR C677T polymorphism on HPV infection and development of cervical cancer can be modified by levels of folic acid [27, 42]. MTHFR polymorphism associated with low folate levels leads to changes in DNA

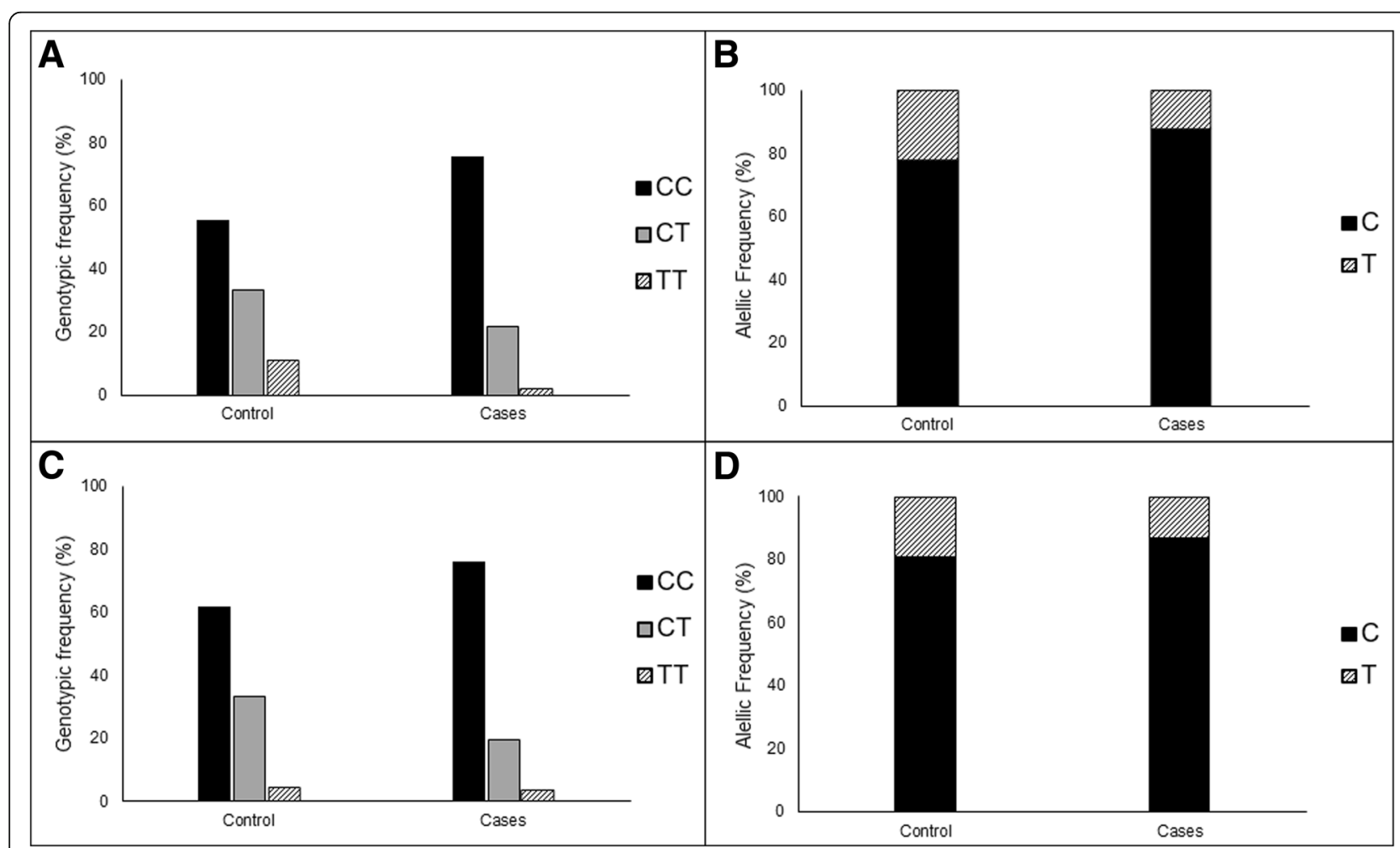

Fig. 5 Association between MTHFR C677T polymorphism and cervical lesions according to the age group. Frequencies of CC, CT and TT genotypes $(\mathbf{a}, \mathbf{c})$, and $\mathrm{C}$ and $\mathrm{T}$ alleles $(\mathbf{b}, \mathbf{d})$ among women with age $\leq 30$ years old $(\mathbf{a}, \mathbf{b})$ and $>30$ years old $(\mathbf{c}, \mathbf{d})$ in Control and Case groups. Note: Three samples were excluded due to lack of age data 
methylation pattern of host cells as well as in HPV genome, which causes changes in gene expression that could lead to infection persistence. In addition, DNA integrity may be compromised, increasing chance of integration of HPV genetic material into host DNA, a key process for progression of infection to cancer [43].

\section{Conclusions}

In summary, no association between MTHFR C677T polymorphism, HPV infection and cervical intraepithelial neoplasia was found.

\section{Abbreviations \\ C: Cytosine; CIN: Cenvical Intraepithelial Neoplasia; dNTP: Deoxyribonucleotide; HPV: Human Papillomavirus; hr-HPV: high-risk Huma Papillomavirus; HWE: Hardy- Weinberg Equilibrium; MTHFR: Methylenetetrahydrofolate reductase; PCR: Polymerase Chain Reaction; RFLP: Restriction Fragment Length Polymorphism; SCC: Squamous Cervical Carcinoma; SNP: Single Nucleotide Polymorphism; T: Thymine}

\section{Acknowledgements}

To Laboratório de Análises Clínicas (LAPAC) for infrastructure, and Coordenação de Aperfeiçoamento de Pessoal de Nível Superior (CAPES) for scholarship.

\section{Authors' contributions}

NNTS, APS, and AAL analyzed and interpreted the patient data regarding the HPV infection and MTHFR genotype. AT provided all samples, analyzed and interpreted the patient data regarding histopathologic abnormalities. All authors read and approved the final manuscript.

\section{Funding}

This work was supported by grants from Fundação de Amparo à Pesquisa do Estado de Minas Gerais - FAPEMIG (APQ02807-10), and Pró-reitoria de Pós-Graduação e Pesquisa - PROPP/UFOP (082017013).

\section{Availability of data and materials}

The datasets used and/or analyzed during the current study are available from the corresponding author on reasonable request.

\section{Ethics approval and consent to participate}

The block biopsies analyzed in this study were part of archive of Tafuri Laboratory, a laboratory of pathological anatomy. Therefore, we did not perform new collection of samples specifically for this study, and there was no direct contact with patients. Then, it was not requested written or verbal consent for each women. The need for consent was waived by Research Ethics Committee of the Federal University of Ouro Preto, approved the study (CAAE: 0022.0.238.000-10).

\section{Consent for publication}

Not applicable.

\section{Competing interests}

The authors declare that they have no competing interests.

\begin{abstract}
Author details
'Programa de Pós-Graduação em Ciências Farmacêuticas, Departamento de Análises Clínicas, Universidade Federal de Ouro Preto, Ouro Preto, Minas Gerais 35400-000, Brazil. '2Departamento de Análises Clínicas e Toxicológicas, Universidade Federal de Minas Gerais, President Antônio Carlos Avenue 6627, Belo Horizonte, Minas Gerais 31270-901, Brazil. " Laboratório Tafuri, São Paulo Street, 893, Belo Horizonte, Minas Gerais 30170-131، Brazil.
\end{abstract}

Received: 31 August 2018 Accepted: 21 May 2019

Published online: 06 June 2019

\section{References}

1. Ferlay J, et al. Globocan 2012: Cancer Incidence and Mortality in 2012 v1.0. In: Cancer Incidence and Mortality Worldwide, vol. 11. Lyon: International Agency for Research on Cancer, World Health Organization; 2013.
2. INCA. Estimativa 2018 - Incidência de Câncer no Brasil. Rio de Janeiro: Instituto Nacional do Câncer José Alencar Gomes da Silva, Ministério da Saúde; 2018. p. 130.

3. zur Hausen $\mathrm{H}$. Papillomaviruses and cancer: from basic studies to clinical application,(in eng). Nat Rev Cancer. 2002;2(5):342-50. https://doi.org/10. 1038/nrc798.

4. Schiffman M, Wentzensen N. Human papillomavirus infection and the multistage carcinogenesis of cervical cancer, (in eng). Cancer Epidemiol Biomark Prev. 2013;22(4):553-60. https://doi.org/10.1158/1055-9965.EPI-12-1406.

5. Fang J, Zhang $\mathrm{H}$, Jin $\mathrm{S}$. Epigenetics and cervical cancer: from pathogenesis to therapy, (in eng). Tumour Biol. 2014;35(6):5083-93. https://doi.org/10 1007/s13277-014-1737-z.

6. Castellsagué X, Muñoz N. Chapter 3: cofactors in human papillomavirus carcinogenesis--role of parity, oral contraceptives, and tobacco smoking, (in eng). J Natl Cancer Inst Monogr. 2003:(31):20-8.

7. Fox JT, Stover PJ. Folate-mediated one-carbon metabolism, (in eng). Vitam Horm. 2008:79:1-44. https://doi.org/10.1016/S0083-6729(08)00401-9.

8. Frosst $\mathrm{P}$, et al. A candidate genetic risk factor for vascular disease: a common mutation in methylenetetrahydrofolate reductase, (in eng). Nat Genet. 1995;10(1):111-3. https://doi.org/10.1038/ng0595-111.

9. Trimmer EE. Methylenetetrahydrofolate reductase: biochemical characterization and medical significance, (in eng). Curr Pharm Des. 2013;19(14):2574-93.

10. Kim YI. Role of the MTHFR polymorphisms in cancer risk modification and treatment, (in eng). Future Oncol. 2009;5(4):523-42. https://doi.org/ 10.2217/fon.09.26

11. Ueland PM, Hustad S, Schneede J, Refsum H, Vollset SE. Biological and clinical implications of the MTHFR C677T polymorphism, (in eng). Trends Pharmacol Sci. 2001;22(4):195-201.

12. Kim YI. 5,10-methylenetetrahydrofolate reductase polymorphisms and pharmacogenetics: a new role of single nucleotide polymorphisms in the folate metabolic pathway in human health and disease, (in eng). Nutr Rev. 2005:63(11):398-407

13. Wu CY, Yang M, Lin M, Li LP, Wen XZ. MTHFR C677T polymorphism was an ethnicity-dependent risk factor for cervical cancer development: evidence based on a meta-analysis, (in eng). Arch Gynecol Obstet. 2013. https://doi. org/10.1007/s00404-013-2721-3.

14. Yu L, Chang K, Han J, Deng S, Chen M. Association between methylenetetrahydrofolate reductase C677T polymorphism and susceptibility to cervical cancer: a meta-analysis, (in eng). PLoS One. 2013; 8(2):e55835. https://doi.org/10.1371/journal.pone.0055835.

15. Richart RM. The natural history of cervical intraepithelial neoplasia. Clin Obstret Gynecol. 1967:10:748-84.

16. Kleter $B$, et al. Novel short-fragment PCR assay for highly sensitive broadspectrum detection of anogenital human papillomaviruses, (in eng). Am J Pathol. 1998:153(6):1731-9. https://doi.org/10.1016/S0002-9440(10)65688-X.

17. Silva NNT, Reis LES, Lima AA. Comparison of capillary electrophoresis, AGE, and PAGE for MTHFR polymorphism analysis in FFPE cervical samples, (in eng). Ann Clin Lab Sci. 2018;48(5):587-93.

18. Rousset F. genepop'007: a complete re-implementation of the genepop software for windows and Linux, (in eng). Mol Ecol Resour. 2008;8(1):103-6. https://doi.org/10.1111/j.1471-8286.2007.01931.x.

19. Rodriguez S, Gaunt TR, Day IN. Hardy-Weinberg equilibrium testing of biological ascertainment for Mendelian randomization studies, (in eng). Am J Epidemiol. 2009;169(4):505-14. https://doi.org/10.1093/aje/kwn359.

20. Choi SW, Mason JB. Folate and carcinogenesis: an integrated scheme, (in eng). J Nutr. 2000;130(2):129-32.

21. Henao $\mathrm{OL}$, et al. Women with polymorphisms of methylenetetrahydrofolate reductase (MTHFR) and methionine synthase (MS) are less likely to have cervical intraepithelial neoplasia (CIN) 2 or 3, (in eng). Int J Cancer. 2005; 113(6):991-7. https://doi.org/10.1002/ijc.20695.

22. Lambropoulos AF, et al. Methylenetetrahydrofolate reductase polymorphism C677T is not associated to the risk of cervical dysplasia, (in eng). Cancer Lett. 2003;191(2):187-91.

23. Prasad W, Wilkhoo H. Association of the functional polymorphism C677T in the methylenetetrahydrofolate reductase gene with colorectal, thyroid, breast, ovarian, and cervical cancers, (in eng). Onkologie. 2011;34(8-9):422-6. https:// doi.org/10.1159/000331131.

24. Kohaar I, et al. Homocysteine levels are associated with cervical cancer independent of methylene tetrahydrofolate reductase gene (MTHFR) polymorphisms in Indian population, (in eng). Biomarkers. 2010;15(1):61-8. https://doi.org/10.3109/13547500903295881. 
25. Mostowska A, Myka M, Lianeri M, Roszak A, Jagodziński PP. Folate and choline metabolism gene variants and development of uterine cervical carcinoma, (in eng). Clin Biochem. 2011;44(8-9):596-600. https://doi.org/10. 1016/j.clinbiochem.2011.02.007.

26. Delgado-Enciso I, et al. The effect of MTHFR polymorphisms, pregnancy and first intercourse on cervical cancer in a population from the northeastern Mexico], (in spa. Rev Invest Clin. 2006;58(5):462-9.

27. Badiga S, et al. A lower degree of PBMC L1 methylation in women with lower folate status may explain the MTHFR C677T polymorphism associated higher risk of CIN in the US post folic acid fortification era, (in eng). PLoS One. 2014;9(10):e110093. https://doi.org/10.1371/journal.pone.0110093.

28. Long S, Yang X, Liu X, Yang P. Methylenetetrahydrofolate reductase (MTHFR) polymorphisms and susceptibility for cervical lesions: a meta-analysis, (in eng). PLoS One. 2012;7(12):e52381. https://doi.org/10.1371/journal.pone.0052381.

29. Xu XJ, Zou LW, Wang DB. Cervical cancer with polymorphism in MTHFR C677T gene: a systematic review and meta-analysis, (in eng). Mol Biol Rep. 2013;40(1):255-62. https://doi.org/10.1007/s11033-012-2056-3.

30. Yi K, Yang L, Lan Z, Xi M. The association between MTHFR polymorphisms and cervical cancer risk: a system review and meta analysis, (in eng). Arch Gynecol Obstet. 2016. https://doi.org/10.1007/s00404-016-4037-6.

31. Gong JM, Shen Y, Shan WW, He YX. The association between MTHFR polymorphism and cervical cancer, (in eng). Sci Rep. 2018;8(1):7244. https:// doi.org/10.1038/s41598-018-25726-9.

32. Piyathilake CJ, et al. Protective association of MTHFR polymorphism on cervical intraepithelial neoplasia is modified by riboflavin status, (in eng). Nutrition. 2007;23(3):229-35. https://doi.org/10.1016/j.nut.2006.12.006.

33. Hajiesmaeil M, Tafvizi F, Sarmadi S. The effect of methylenetetrahydrofolate reductase polymorphisms on susceptibility to human papilloma virus infection and cervical cancer, (in eng). Infect Genet Evol. 2016;46:1-6. https://doi.org/10.1016/j.meegid.2016.10.012.

34. Tomita LY, D'Almeida V, Villa LL, Franco EL, Cardoso MA, B. S. Group. Polymorphisms in genes involved in folate metabolism modify the association of dietary and circulating folate and vitamin B-6 with cervical neoplasia, (in eng). J Nutr. 2013;143(12):2007-14. https://doi.org/10.3945/jn.113.182212.

35. Zhu J, Wu L, Kohlmeier M, Ye F, Cai W. Association between MTHFR C677T, MTHFR A1298C and MS A2756G polymorphisms and risk of cervical intraepithelial neoplasia II/III and cervical cancer: a meta-analysis, (in eng). Mol Med Rep. 2013;8(3):919-27. https://doi.org/10.3892/mmr.2013.1589.

36. Guo LN. Methylenetetrahydrofolate reductase C677T polymorphism and cervical cancer risk: a meta-analysis, (in eng). Asian Pac J Cancer Prev. 2012;13(5):2193-7.

37. Nandan NK, et al. Allelic variations in 5, 10-methylenetetrahydrofolate reductase gene and susceptibility to cervical cancer in Indian women, (in eng). Drug Metab Lett. 2008;2(1):18-22.

38. Botezatu A, et al. Methylenetetrahydrofolate reductase (MTHFR) polymorphisms and promoter methylation in cervical oncogenic lesions and cancer, (in eng). J Cell Mol Med. 2013;17(4):543-9. https://doi.org/10.1111/jcmm.12032.

39. Goodman MT, et al. Association of methylenetetrahydrofolate reductase polymorphism C677T and dietary folate with the risk of cervical dysplasia, (in eng). Cancer Epidemiol Biomark Prev. 2001;10(12):1275-80.

40. INCA. Diretrizes brasileiras para o rastreamento do câncer do colo do útero. Rio de Janeiro: Instituto Nacional do Câncer José Alencar Gomes da Silva, Ministério da Saúde; 2016. p. 118.

41. Sull JW, et al. The effect of methylenetetrahydrofolate reductase polymorphism C677T on cervical cancer in Korean women, (in eng). Gynecol Oncol. 2004; 95(3):557-63. https://doi.org/10.1016/j.ygyno.2004.08.008.

42. Tong SY, et al. Common polymorphisms in methylenetetrahydrofolate reductase gene are associated with risks of cervical intraepithelial neoplasia and cervical cancer in women with low serum folate and vitamin B12, (in eng). Cancer Causes Control. 2011;22(1):63-72. https://doi.org/10.1007/ s10552-010-9675-6.

43. Peter $M$, et al. Frequent genomic structural alterations at HPV insertion sites in cervical carcinoma, (in eng). J Pathol. 2010;221(3):320-30. https://doi.org/ 10.1002/path.2713.

\section{Publisher's Note}

Springer Nature remains neutral with regard to jurisdictional claims in published maps and institutional affiliations.

\section{Ready to submit your research? Choose BMC and benefit from:}

- fast, convenient online submission

- thorough peer review by experienced researchers in your field

- rapid publication on acceptance

- support for research data, including large and complex data types

- gold Open Access which fosters wider collaboration and increased citations

- maximum visibility for your research: over $100 \mathrm{M}$ website views per year

At BMC, research is always in progress.

Learn more biomedcentral.com/submissions 